\title{
Frequency of consumption of specific food items and symptoms of preeclampsia and eclampsia in Indian women
}

\begin{abstract}
Background: Preeclampsia/eclampsia is responsible for upwards of $20 \%$ of maternal morbidity and mortality in developing countries. Objective: We examined the relationship between frequency of food intake and symptoms of preeclampsia eclampsia and eclampsia among Indian women aged 15-49 $(n=39,657)$ for the most recent live birth in the 5 years preceding the National Family Health Survey-3 (2005-2006). Multiple logistic regression analysis was used to estimate the association between frequency of intake of specific food items, and self-reported symptoms of preeclampsia eclampsia and eclampsia, adjusting for maternal age, and other potential socio-demographic confounders. Results: Daily consumption of milk or curd (odds ratio [OR]: $0.88 ; 95 \%$ confidence interval [Cl]: 0.81-0.96), green leafy vegetables, chicken/meat and weekly pulses/beans consumption are associated with substantially lower risk of preeclampsia eclampsia. Eclampsia risk is higher among those who consumed fruits (ORs ranges from 1.18 to 1.44 ) and chicken/meat occasionally (OR: $1.28 ; 95 \% \mathrm{Cl}: 1.11-1.48$ ), and lower among those consuming vegetables daily. Conclusion: Frequency of consumption of specific food items is associated with occurrence of preeclampsia eclampsia and eclampsia symptoms in Indian women.
\end{abstract}

Key words: Preeclampsia, eclampsia, food types, frequency of intake, India, National Family Health Survey-3, women

\section{INTRODUCTION}

Preeclampsia and eclampsia pose significant threats to maternal health, particularly in developing countries. In low-and middle-income settings, these two conditions affect approximately $8 \%$ of all pregnancies, causing an estimated $15-20 \%$ of maternal morbidity and mortality. ${ }^{[1]}$ Preeclampsia is a life-threatening complication of pregnancy that typically starts after the $20^{\text {th }}$ week of gestation. Women with preeclampsia may present with symptoms such as headache, upper abdominal pain, or visual disturbances and have raised blood pressure, ankle edema and proteinuria. When preeclampsia is left untreated or is severe, giving rise to seizures/convulsions, which cannot be attributed to other causes (such as epilepsy), the condition is known as eclampsia. Although several studies have found that micronutrient deficiencies, such as iron, Vitamin A, Vitamin C, and calcium contribute to preeclampsia risks, ${ }^{[2-5]}$ few studies have actually evaluated the potential role of different food types.

Existing nutritional evidence is highly variable ${ }^{[6]}$ regarding its association with preeclampsia and eclampsia risk. Some studies suggest that dietary patterns may influence maternal antioxidant levels, mediating the link between preeclampsia and oxidative stress, an established risk factor. ${ }^{[7]}$ However, consumption of high-energy diets may increase the risk of preeclampsia by inducing abnormal lipid metabolism while consumption of dietary fiber may regulate these metabolic processes, thereby reducing risk. ${ }^{[8]}$ However, studies that have attempted to test these links empirically have not been conducted in developing countries where majority burden falls, nor have they employed appropriate multivariate models to predict the determinants. To the best of our knowledge, there has not been any previous large-scale report concerning the dietary risk factors for preeclampsia and eclampsia in Indian women. In this study, we evaluate potential dietary risk factors of preeclampsia and eclampsia, using a large representative sample of Indian mothers in the third National Family Health Survey (NFHS) conducted during 2005-2006. 


\section{MATERIALS AND METHODS}

\section{Study location and population}

Data were taken from the most recent wave of the NFHS-3, 2005-2006), India's demographic and health surveys. NFHS-3 collected demographic, socioeconomic and health information from a nationally representative probability sample of 124,385 women aged 15-49 residing in 109,341 households. The sample is a multistage cluster sample with an overall response rate of $98 \%$. All states of India are represented in the sample (except the small Union Territories), covering more than 99\% of the country's population. Full details of the survey are available elsewhere. ${ }^{[9]}$ The analysis presented here focuses on 39,657 women in the sample who report being married and who have had a live birth in the 5 years preceding the survey. The survey was conducted using an interviewer-administered questionnaire in the native language of the respondent.

\section{Assessment of pre eclampsia and eclampsia symptoms}

To assess the symptoms of pre eclampsia, mothers were asked if at any time during their last pregnancy they experienced relevant symptoms, including difficulty with vision during daylight, night blindness, convulsions (not from fever), swelling of the legs, body or face, excessive fatigue, or vaginal bleeding. According to the WHO criteria (2007), ${ }^{[10]}$ women who reported difficulty with vision during daylight, swelling of the legs, body, or face, or excessive fatigue were coded as having symptoms of pre eclampsia, whereas those who reported experiencing convulsions (not from fever) were coded as symptomatic eclampsia. ${ }^{[10]}$ Data on blood pressure and proteinuria during pregnancy were not available in NFHS-3. Dietary intake variables were based on the self-reported frequency of consumption of milk or curd, green leafy vegetables, fruits, pulses and beans, eggs, fish, chicken or meat, categorized into daily, weekly, occasionally, or never. Potential confounders and covariates were selected on the basis of previous knowledge of their association with pre eclampsia/eclampsia in high-income countries. We used multiple logistic regression to estimate the association between frequency of dietary intake and preeclampsia eclampsia and eclampsia risk after adjusting for maternal factors, biological and lifestyle factors and socio-demographic characteristics of the mothers. Models were adjusted for sampling weights. ${ }^{[9]}$ All analyses were conducted using the SPSS statistical software package Version 19 (IBM SPSS Statistics, Chicago, Illinois, USA).

\section{Ethical considerations}

The NFHS-3 survey received ethical approval from the International Institute for Population Science's Ethical Review Board and the Indian Government. Prior informed written consent was obtained from each respondent. The analysis presented in this study is based on secondary analysis of the existing survey data with all identifying information removed.

\section{RESULTS}

Overall 55.6\% of mothers reported preeclamspia eclampsia symptoms, and 10.3\% reported eclampsia. Table 1 reports the results of our statistical models. After adjusting for maternal, biological, and chronic disease risk factors, as well as sociodemographic characteristics, the risk of pre-eclampsia was found significantly lower among women who consumed milk daily (odds ratio $[\mathrm{OR}]: 0.88 ; 95 \%$ confidence interval $[\mathrm{CI}]: 0.81-0.96)$, green leafy vegetables daily or weekly (OR: 0.69-0.76), pulses or beans at least weekly or occasionally (ORs ranges from 0.84 to 0.92 ), fruits daily (OR: 0.92), eggs weekly or occasionally, consumes fish (OR: 0.90$)$ or chicken or meat daily or occasionally, with added reference to those who never consumed them. However, a greater risk of pre eclampsia was found among women consuming fruits weekly or occasionally (OR: 1.11), eggs daily (OR: 1.23) and fish weekly (OR: 1.22).

The risk of eclampsia was lower among those consuming green leafy vegetables (ORs ranges from 0.74 to 0.79 ), consuming fish weekly or occasionally (ORs ranges from 0.44 to 0.62 ), eggs weekly or occasionally (ORs ranges from 0.61 to 0.76 ), but was higher among those who consumed fruits (ORs ranges from 1.18 to 1.44), chicken or meat occasionally (OR: 1.28; 95\% CI: 1.11-1.48) with reference to those who never consumed them.

\section{DISCUSSION}

This study provides empirical evidence of an association between the frequency of intake of specific food items and symptoms of pre eclampsia and eclampsia in a large nationally representative sample of Indian women. The findings suggest that the frequency of consumption of specific food items has a substantial effect on the occurrence of symptoms suggestive of preeclampsia eclampsia or eclampsia in Indian women.

Maternal nutritional status and dietary intake has long been hypothesized to have a role in the pathophysiology of pre eclampsia/ eclampsia. ${ }^{[11-13]}$ There is increasing evidence lately that nutrition plays an important role in preventing hypertensive disorders ${ }^{[14]} \mathrm{a}$ finding potentially salient to eclampsia as a hypertensive condition. A 3 week U.S. based clinical trial ${ }^{[15]}$ found that, a diet rich in fruits and vegetables is associated with a decline in blood pressure, with higher magnitude effects for participants with existing hypertensive conditions. In India, two studies ${ }^{[14,16]}$ have shown that higher intake of fruit and vegetables is linked to a lower risk of cardiovascular diseases, including hypertension but a study among Zimbabwean women found that variation in consumption of specific food items does not have a strong effect on the incidence of preeclampsia. ${ }^{[17]}$ The possible pathway might be that; dietary patterns influence antioxidant levels, mediating the link between pre eclampsia and oxidative stress, an established risk factor for eclampsia. ${ }^{[2,7]}$ Oxidative stress, driven in part by insufficient antioxidant defenses, lowers, polyunsaturated fatty acid levels, which are hypothesized to serve a protective function against vascular endothelial damage. ${ }^{[18]}$ Some 


\begin{tabular}{|c|c|c|c|c|}
\hline \multirow[t]{3}{*}{ Predictors } & \multicolumn{2}{|c|}{ Pre-eclampsia } & \multicolumn{2}{|c|}{ Eclampsia } \\
\hline & Unadjusted & Adjusted $^{*}$ & Unadjusted & Adjusted* $^{*}$ \\
\hline & OR $[95 \% \mathrm{Cl}]$ & OR $[95 \% \mathrm{Cl}]$ & OR $[95 \% \mathrm{Cl}]$ & OR $[95 \% \mathrm{Cl}]$ \\
\hline \multicolumn{5}{|c|}{ Frequency of intake of specific food items } \\
\hline \multicolumn{5}{|l|}{ Milk or curd } \\
\hline Never Ref & 1.00 & 1.00 & 1.00 & 1.00 \\
\hline Occasionally & $1.06[0.99-1.14]$ & $0.97[0.89-1.06]$ & $1.08[0.97-1.20]$ & $1.02[0.89-1.18]$ \\
\hline Weekly & $0.99[0.92-1.07]$ & $1.04[0.94-1.15]$ & $1.03[0.92-1.17]$ & $0.99[0.84-1.17]$ \\
\hline Daily & $0.78[0.73-0.84]$ & $0.88[0.81-0.96]$ & $0.76[0.68-0.85]$ & $0.98[0.84-1.14]$ \\
\hline \multicolumn{5}{|l|}{ Pulses and beans } \\
\hline Never Ref & 1.00 & 1.00 & 1.00 & 1.00 \\
\hline Occasionally & $0.94[0.74-1.20]$ & $0.97[0.72-1.30]$ & $1.33[0.86-2.05]$ & $1.26[076-2.09]$ \\
\hline Weekly & $0.98[0.77-1.25]$ & $0.84[0.76-0.92]$ & $1.20[0.78-1.80]$ & $1.12[0.95-1.32]$ \\
\hline Daily & $1.03[0.80-1.32]$ & $0.92[0.83-1.01]$ & $1.28[0.82-2.00]$ & $0.99[0.85-1.17]$ \\
\hline \multicolumn{5}{|l|}{ Green leafy vegetables } \\
\hline Never/Occasionally Ref & 1.00 & 1.00 & 1.00 & 1.00 \\
\hline Weekly & $0.88[0.81-0.96]$ & $0.76[0.68-0.84]$ & $0.83[0.73-0.95]$ & $0.74[0.62-0.88]$ \\
\hline Daily & $0.87[0.80-0.094]$ & $0.69[0.62-0.77]$ & 0.87 [0.77-0.99] & $0.79[0.67-0.94]$ \\
\hline \multicolumn{5}{|l|}{ Fruits } \\
\hline Never Ref & 1.00 & 1.00 & 1.00 & 1.00 \\
\hline Occasionally & 0.93 [0.83-1.02] & $1.11[1.05-1.19]$ & $0.76[0.66-0.86]$ & $1.18[1.06-1.31]$ \\
\hline Weekly & 0.87 [0.78-0.97] & $1.11[1.01-1.22]$ & $0.60[0.52-0.71]$ & $1.28[1.09-1.52]$ \\
\hline Daily & $0.81[0.72-0.91]$ & $0.92[0.80-1.06]$ & $0.49[0.41-0.59]$ & $1.44[1.17-1.76]$ \\
\hline \multicolumn{5}{|l|}{ Eggs } \\
\hline Never Ref & 1.00 & 1.00 & 1.00 & 1.00 \\
\hline Occasionally & 1.15 [1.10-1.21] & $0.97[0.90-1.04]$ & $1.10[1.02-1.18]$ & $0.76[0.68-0.86]$ \\
\hline Weekly & 1.00 [0.95-1.05] & $0.86[0.75-1.00]$ & $0.64[0.58-0.70]$ & $0.61[0.45-0.83]$ \\
\hline Daily & 0.99 [0.88-1.12] & $1.23[1.11-1.36]$ & $0.53[0.41-0.67]$ & $1.08[0.92-1.27]$ \\
\hline \multicolumn{5}{|l|}{ Fish } \\
\hline Never Ref & 1.00 & 1.00 & 1.00 & 1.00 \\
\hline Occasionally & 1.23 [1.17-1.29] & $0.90[0.83-0.98]$ & $1.22[1.13-1.31]$ & $0.62[0.54-0.72]$ \\
\hline Weekly & 1.10 [1.04-1.16] & $1.22[1.08-1.37]$ & $0.73[0.68-0.81]$ & $0.44[0.35-0.57]$ \\
\hline Daily & 1.65 [1.50-1.81] & $0.97[0.87-1.07]$ & $0.45[0.34-0.55]$ & $0.98[0.81-1.17]$ \\
\hline \multicolumn{5}{|l|}{ Chicken or meat } \\
\hline Never Ref & 1.00 & 1.00 & 1.00 & 1.00 \\
\hline Occasionally & 1.28 [1.23-1.34] & $0.87[0.81-0.94]$ & 1.08 [1.01-1.16] & $1.28[1.11-1.48]$ \\
\hline Weekly & $0.90[0.85-0.95]$ & $0.97[0.74-1.27]$ & $0.66[0.60-0.73]$ & $1.51[0.98-2.34]$ \\
\hline Daily & 1.38 [1.11-1.72] & $0.87[0.77-0.98]$ & $1.03[0.73-1.46]$ & $0.99[0.81-1.21]$ \\
\hline
\end{tabular}

Ref indicates Reference category, * Odds ratios adjusted for maternal, biological, and lifestyle factors and sociodemographic characteristics

studies $^{[19]}$ suggest that inadequate antioxidant and folate intake may contribute to oxidative stress and thereby increase the risk of preeclampsia eclampsia. Lycopene, an antioxidant found in many red fruits and vegetables, also has been associated with a reduced risk. ${ }^{[20]}$

The strengths of our study include the large nationally representative study sample and the population-level focus on the predictors of pre eclampsia and eclampsia. However, due to the general challenges of measuring hypertensive disorders in population-based studies, the information of the symptoms of preeclampsia eclampsia and eclampsia presented here is based on self-reports and should, therefore, be interpreted with caution. Although we cannot exclude misclassification within this context, it is unlike that we missed severe preeclampsia eclampsia and eclampsia cases. Also, we could not identify the gestational onset of pre eclampsia. We included various symptoms of health problems during the last pregnancy of women during the 5 years preceding the survey as a proxy measure for preeclampsia eclampsia and eclampsia, which is likely to be a poor proxy, but this is the best we have at the national level. The 55.6\% and $10.3 \%$ prevalence of preeclampsia eclampsia and eclampsia symptoms respectively is probably too high in a population that might likely to be due to over-reporting. It is likely that some women do not understand the question and thus could have overtly reported the symptoms experienced during pregnancy. Although we adjusted for several confounding variables, we cannot exclude the possibility of residual confounding in this study. In these analyses, the crosssectional design precludes causal inferences, and we were limited to the questions used to obtain lifestyle and dietary information. ${ }^{[1]}$

Globally and more specifically in developing countries, few population level studies exist which assess the dietary determinants of preeclampsia and eclampsia. This study is important because 
few studies have reported preeclampsia/eclampsia prevalence rates based on population-level data in India. This study implicates that dietary risk factors for preeclampsia and eclampsia exists, and thus there is a need for replication of findings given that the dietary patterns are modifiable. Our study findings may serve as an important call for health care providers to heighten their awareness of the increased population-level risk for preeclampsia and eclampsia disease originating in pregnancy. With the target of the millennium development goals in sight, preeclampsia/eclampsia should be identified as one of the priority areas in reducing maternal and infant mortality and morbidity in India. However, further research involving the use of a more comprehensive dietary measure, pre pregnancy assessment of all the risk factors and ascertainment of dietary intake prior to the development of preeclampsia and eclampsia and accuracy of reporting of the symptoms of preeclampsia and eclampsia are needed in a developing country setting.

\section{REFERENCES}

1. Sibai B, Dekker G, Kupferminc M. Pre-eclampsia. Lancet 2005;365:785-99.

2. Bilodeau JF, Hubel CA. Current concepts in the use of antioxidants for the treatment of preeclampsia. J Obstet Gynaecol Can 2003;25:742-50.

3. Bodnar LM, Tang G, Ness RB, Harger G, Roberts JM. Periconceptional multivitamin use reduces the risk of preeclampsia. Am J Epidemiol 2006;164:470-7.

4. Jain S, Sharma P, Kulshreshtha S, Mohan G, Singh S. The role of calcium, magnesium, and zinc in pre-eclampsia. Biol Trace Elem Res 2010;133:162-70.

5. Levine RJ, Hauth JC, Curet LB, Sibai BM, Catalano PM, Morris CD, et al. Trial of calcium to prevent preeclampsia. $\mathrm{N}$ Engl $\mathrm{J}$ Med 1997;337:69-76.

6. Roberts JM, Balk JL, Bodnar LM, Belizán JM, Bergel E, Martinez A. Nutrient involvement in preeclampsia. J Nutr 2003;133 5 Suppl 2:1684S-92.

7. Scholl TO, Leskiw M, Chen X, Sims M, Stein TP. Oxidative stress, diet, and the etiology of preeclampsia. Am J Clin Nutr 2005;81:1390-6.

8. $\mathrm{Xu} \mathrm{H}$, Shatenstein B, Luo ZC, Wei S, Fraser W. Role of nutrition in the risk of preeclampsia. Nutr Rev 2009;67:639-57.
9. International Institute for Population Sciences (IIPS) and Macro International National Family Health Survey (NFHS-3), 2005-06: India. Mumbai: International Institute for Population Sciences; 2007.

10. World Health Organisation. Integrated Management of Pregnancy and Childbirth: Managing complications in pregnancy and childbirth: A guide for midwives and doctors. Department of Reproductive Health and Research. WHO, Geneva; 2007.

11. Chesley LC. Hypertensive Disorders of Pregnancy. New York: AppletonCentury-Crofts; 1978.

12. Roberts JM. Recent advances: obstetrics. BMJ 2000;321:33-5.

13. Roberts JM, Bodnar LM. Report on the WIC Nutrition Risk Criterion for Hypertension in Pregnancy. Prepared for the US Department of Agriculture, Food and Nutrition Service; 2007.

14. Srinath Reddy K, Katan MB. Diet, nutrition and the prevention of hypertension and cardiovascular diseases. Public Health Nutr 2004;7:167-86.

15. Sacks FM, Appel LJ, Moore TJ, Obarzanek E, Vollmer WM, Svetkey LP, et al. A dietary approach to prevent hypertension: A review of the Dietary Approaches to Stop Hypertension (DASH) Study. Clin Cardiol 1999;22:III6-10.

16. Radhika G, Sudha V, Mohan Sathya R, Ganesan A, Mohan V. Association of fruit and vegetable intake with cardiovascular risk factors in urban south Indians. Br J Nutr 2008;99:398-405.

17. Atkinson JO, Mahomed K, Williams MA, Woelk GB, Mudzamiri S, Weiss NS. Dietary risk factors for pre-eclampsia among women attending Harare Maternity Hospital, Zimbabwe. Cent Afr J Med 1998;44:86-92.

18. Mehendale S, Kilari A, Dangat K, Taralekar V, Mahadik S, Joshi S. Fatty acids, antioxidants, and oxidative stress in pre-eclampsia. Int J Gynaecol Obstet 2008;100:234-8.

19. Roberts JM, Lain KY. Recent Insights into the pathogenesis of preeclampsia. Placenta 2002;23:359-72.

20. Sharma JB, Sharma A, Bahadur A, Vimala N, Satyam A, Mittal S. Oxidative stress markers and antioxidant levels in normal pregnancy and pre-eclampsia. Int J Gynaecol Obstet 2006;94:23-7.

21. Pullum TW. An Assessment of the Quality of Data on Health and Nutrition in the DHS Surveys, 1993-2003. Methodological Reports No. 6. Calverton, Maryland, USA: Macro International Inc.; 2008.

How to cite this article: Agrawal S. Frequency of consumption of specific food items and symptoms of preeclampsia and eclampsia in Indian women. Int J Med Public Health 2014;4:350-3.

Source of Support: Nil, Conflict of Interest: The authors declared no conflicts of interest.

\section{New features on the journal's website}

Optimized content for mobile and hand-held devices

HTML pages have been optimized of mobile and other hand-held devices (such as iPad, Kindle, iPod) for faster browsing speed.

Click on [Mobile Full text] from Table of Contents page.

This is simple HTML version for faster download on mobiles (if viewed on desktop, it will be automatically redirected to full HTML version)

\section{E-Pub for hand-held devices}

EPUB is an open e-book standard recommended by The International Digital Publishing Forum which is designed for reflowable content i.e. the text display can be optimized for a particular display device.

Click on [EPub] from Table of Contents page.

There are various e-Pub readers such as for Windows: Digital Editions, OS X: Calibre/Bookworm, iPhone/iPod Touch/iPad: Stanza, and Linux: Calibre/Bookworm.

\section{E-Book for desktop}

One can also see the entire issue as printed here in a 'flip book' version on desktops.

Links are available from Current Issue as well as Archives pages.

Click on View as eBook 